(DOI: 10.24874/jsscm.2017.11.01.03)

\title{
Thermodynamic Optimization and Phase Modeling in the Ni-Sn-Bi Ternary System
}

\author{
V. Gandova ${ }^{1, *}$, K. Lilova ${ }^{2}$ \\ ${ }^{1}$ Inorganic and Physical Chemistry Department, University of Food Technologies, Plovdiv, \\ Bulgaria \\ e-mail: gandova_71@abv.bg \\ ${ }^{2}$ Peter A. Rock Thermochemistry Laboratory, University of California at Davis, Davis, USA \\ e-mail: k_lilova@yahoo.com \\ *corresponding author
}

\begin{abstract}
The thermodynamic optimization of the Ni-Sn-Bi ternary system was performed using the Calphad method and experimental data obtained by Differential Scanning Calorimetry and Scanning Electron Microscopy. The ternary phase was described using a three-sublattice model. The previously reported new ternary compound and the solubility of the third element in two binary systems ( $\mathrm{Bi}$ in $\mathrm{Ni}-\mathrm{Sn}$ and $\mathrm{Sn}$ in $\mathrm{Bi}-\mathrm{Ni}$ ) were included in the optimization. Four isothermal sections were calculated using Thermi-Calc software and compared with the experimentally obtained ones. A miscibility gap in the ternary system was found at $1610 \mathrm{~K}$.
\end{abstract}

Keywords: Phase modeling, computational thermodynamics, thermodynamic optimization, Calphad method

\section{Introduction}

The development of lead-free solder materials, which will replace the toxic $\mathrm{Sn}-\mathrm{Pb}$ based alloys, is a current challenge and requires a thorough study of the new prospective materials' properties (Kang et al. 1994). The binary Bi-Sn system is one of the potential candidates for lead-free solders due to its low eutectic temperature. In the modern electronic industry, nickel coatings are often plated as a UBM player on the substrate a priori to the soldering of the electronic components. Thus, the investigation of the possible reaction between the solder and the nickel substrate became a necessity. The phases and the thermodynamics of the Ni-Sn-Bi ternary system have already been studied experimentally (Vassilev et al. 2007, 2008, 2009a, Milcheva et al. 2011a, 2011b, Kang et al. 1996, Lee et al. 2003, Vassilev et al. 2012). Calculated phase equilibria at $623 \mathrm{~K}$ have also been reported (Seo et al. 2007), although the authors used binary parameters to describe the ternary solutions. The binary end-systems Bi-Ni (Seo et al. 2007, Vassilev et al. 2009b), Ni-Sn (Liu et al. 2004, Schmetterer et al. 2007, Zemanova et al. 2012) and Bi-Sn (Vizdal et al. 2007) are well known. The solubility of bismuth and tin in the binary Ni-Sn and $\mathrm{Bi}-\mathrm{Ni}$, respectively, has not been extensively studied, although one study shows a small solubility (not more than 2-3 at\%) (Vassilev et al. 2009a). There are three experimentally built isothermal sections at $723 \mathrm{~K}, 903 \mathrm{~K}$ (Vassilev et al. 2009a) and at $1273 \mathrm{~K}$ (Vassilev et al. 2008), which have not been included in any optimizations. The same applies to the new ternary 
compound $\mathrm{T} 1$ with the approximate formula $\mathrm{Ni}_{7} \mathrm{Sn}_{2} \mathrm{Bi}$ and compositions $\mathrm{xNi}=0.66, \mathrm{xSn}=0.21$ and $\mathrm{xBi}=0.13$ (Vassilev et al. 2009a). The thermochemical properties of the ternary system and particularly the liquid phase are not well-known yet. The possible existence of a miscibility gap in the binary Bi-Ni system (Vassilev et al. 2009b) was presented. The purpose of the current optimization is modeling some phases and calculating the phase equilibria in the ternary Ni-SnBi system using experimental data from the authors (Vassilev et al. 2008, Vassilev et al. 2009a, Milcheva et al. 2011).

\section{Literature data}

\subsection{Binary systems}

The Bi-Sn system is a simple eutectic system with no mutual solubility of the two elements. A thermodynamic assessment of the Bi-Sn system was published before (Vizdal et al. 2007; Dinsdale et al. 2008). The thermodynamic description is used in this study (Vizdal et al. 2007).

One liquid phase (L) and four solid phases (two of them intermetallic compounds NiBi and $\mathrm{NiBi}_{3}$ ) are part of the phase equilibria in the Bi-Ni system. The liquid and FCC_A1 phases are treated as substitutional solutions. The phase $(\mathrm{Bi})$ is stoichiometric, while the FCC_A1 Ni contains very small amounts of dissolved bismuth. The $\mathrm{NiBi}_{3}$ compound is stoichiometric, and it is described using the two-sublattice model $(\mathrm{Ni})_{0.25}(\mathrm{Bi})_{0.75}$ (Seo et al. 2007, Vassilev et al. 2008) while the phase $\mathrm{NiBi}$ is described using two or three-sublattice models. The three-sublattice model $(\mathrm{Ni})_{0.333}(\mathrm{Bi})_{0.333}(\mathrm{Bi}, \mathrm{Va})_{0.333}$ (Vassilev et al. 2008) is preferred in the current optimization.

Several thermodynamic optimizations of the binary Ni-Sn phase diagram have been performed (Liu et al. 2004, Zemanova et al. 2012). One of them, done by (Liu et al. 2004), is used for optimization in this work. The Ni-Sn phase diagram consists of one liquid (L), two solid solution phases (FCC_A1 and BCT_A5), and five intermetallic compounds $\mathrm{Ni}_{3} \mathrm{Sn} \_\mathrm{LT}$, $\mathrm{Ni}_{3} \mathrm{Sn} \_\mathrm{HT}, \mathrm{Ni}_{3} \mathrm{Sn}_{2} \_\mathrm{LT}, \mathrm{Ni}_{3} \mathrm{Sn}_{2} \_\mathrm{HT}$ and $\mathrm{Ni}_{3} \mathrm{Sn}_{4}$.

The following models are introduced to modify the descriptions of the binary Ni-Sn phase: $\mathrm{Ni}_{3} \mathrm{Sn}_{2} \mathrm{LT}-(\mathrm{Ni}, \mathrm{Zn})_{0.4}(\mathrm{Ni}, \mathrm{Sn}, \mathrm{Zn})_{0.4}(\mathrm{Sn}, \mathrm{Zn})_{0.2} ; \quad \mathrm{Ni}_{3} \mathrm{Sn}_{2} \mathrm{HT}_{-}-(\mathrm{Ni}, \mathrm{Zn})_{0.33333}(\mathrm{Ni}, \mathrm{Sn}, \mathrm{Zn})_{0.33334}$ $(\mathrm{Sn}, \mathrm{Zn})_{0.33333} ; \mathrm{Ni}_{3} \mathrm{Sn}_{4}-(\mathrm{Ni}, \mathrm{Zn})_{0.25}(\mathrm{Ni}, \mathrm{Sn}, \mathrm{Zn})_{0.25}(\mathrm{Sn}, \mathrm{Zn})_{0.5} ; \mathrm{Ni}_{3} \mathrm{Sn} \_\mathrm{LT}-(\mathrm{Ni}, \mathrm{Zn})_{0.75}(\mathrm{Sn}, \mathrm{Zn})_{0.25} ;$ $\mathrm{Ni}_{3} \mathrm{Sn} \_\mathrm{HT}$ - $(\mathrm{NI}, \mathrm{Sn}, \mathrm{Zn})_{0.25}(\mathrm{NI}, \mathrm{Sn})_{0.25}(\mathrm{Ni})_{0.5}$.

The newest thermodynamic optimization of the Ni-Sn system was performed (Zemanova et al. 2012). The authors treated the low and the high temperature modifications of the $\mathrm{Ni}_{3} \mathrm{Sn}_{2}$ compound $\left(\mathrm{Ni}_{3} \mathrm{Sn}_{2} \mathrm{LT}\right.$ and $\left.\mathrm{Ni}_{3} \mathrm{Sn}_{2} \mathrm{HT}\right)$ as a single phase and therefore their optimization is not used in the current thermodynamic calculations.

\subsection{Ternary system}

One ternary compound $\mathrm{T} 1$ with the formula $\mathrm{Ni}_{7} \mathrm{Sn}_{2} \mathrm{Bi}$ and a homogeneity range is known (Vassilev et al. 2009a) in the Ni-Sn-Bi system. The preferred model is: $(\mathrm{Ni})_{0.7}(\mathrm{Sn}, \mathrm{Va})_{0.2}(\mathrm{Bi}, \mathrm{Ni})_{0.1}$. In the literature, this ternary compound is not described by any thermodynamic model. For this reason, a three-sublattice model is used, since the ternary compound includes three elements in the formula. Va (the symbol "Va'"denotes vacancies) is added in the sublattice of Sn, but $\mathrm{Ni}$ is added in the sublattice of $\mathrm{Bi}$, because this is necessary to describe a homogeneity range.

Three isothermal sections at $723 \mathrm{~K}$ (Vassilev et al. 2009a), $903 \mathrm{~K}$ (Vassilev et al. 2009a) and $1273 \mathrm{~K}$ (Vassilev et al. 2008), the experimental enthalpies of the liquid phase (Vassilev et al. 2008) and the activities of $\mathrm{Bi}$ in the liquid phase in the Ni-Sn-Bi system (Milcheva et al. 2011) were used in this work as experimental results. The bismuth activities of the ternary liquid phase were measured at a certain temperature using a modified isopiestic method. 


\section{Thermodynamic modeling and phase equilibria in the ternary system}

The phase diagram of the Ni-Sn-Bi ternary system was calculated by the calculation of phase diagrams (CALPHAD) method (Lukas et al. 2007). The basic mathematical method used for the calculation of phase equilibria is a constrained minimization of Gibbs energy for the given temperature, pressure and overall composition. This approach is common for all currently available software packages for the modeling of thermodynamic properties and phase diagrams of multicomponent systems (Andersson et al. 2002). The Ni-Sn-Bi system exhibit a number of phases: liquid, RHOMBO_A7 (Bi), FCC_A1 (Ni), NiBi, NiBi, $\mathrm{Ni}_{3} \mathrm{Sn}_{2}$ low and high modification, $\mathrm{Ni}_{3} \mathrm{Sn}$ low and high modification, $\mathrm{Ni}_{3} \mathrm{Sn}_{4}$ and ternary compound T1. The phases of binary systems with their crystallographic data are listed in Table 1.

\begin{tabular}{|c|c|c|c|c|c|c|}
\hline Phase & $\begin{array}{c}\text { Composition } \\
\text { at } \%\end{array}$ & $\begin{array}{l}\text { Pearson } \\
\text { Symbol }\end{array}$ & $\begin{array}{l}\text { Space } \\
\text { group }\end{array}$ & $\begin{array}{c}\text { Structur- } \\
\text { bericht } \\
\text { designation }\end{array}$ & $\begin{array}{l}\text { Proto } \\
- \\
\text { type }\end{array}$ & $\begin{array}{c}\text { Single and } \\
\text { eutectic } \\
\text { temperature } \\
\text { s, K }\end{array}$ \\
\hline FCC_A1 & $\begin{array}{l}0 \sim 10.7 \\
\text { at } \% \mathrm{Sn}\end{array}$ & cF4 & $\operatorname{Fm} \overline{3} \mathrm{~m}$ & A1 & $\mathrm{Cu}$ & 1728.25 \\
\hline$\alpha-S n$ & $\sim 100$ at $\%$ Sn & cF8 & Fd3m & A4 & $\alpha-S n$ & 290 \\
\hline$\beta-S n$ & $\sim 100$ at\% Sn & $\mathrm{tI} 4$ & I4 $4_{1} / \mathrm{amd}$ & A5 & $\beta$-Sn & 505 \\
\hline $\mathrm{Ni}_{3} \mathrm{Sn} \_\mathrm{HT}$ & $\begin{array}{c}24.1 \sim 26.3 \\
\text { at } \% \mathrm{Sn}\end{array}$ & cF16 & $\operatorname{Fm} \overline{3} \mathrm{~m}$ & D03 & $\mathrm{BiF}_{3}$ & 1397 \\
\hline $\mathrm{Ni}_{3} \mathrm{Sn} \_\mathrm{LT}$ & $\begin{array}{c}24.8 \sim 25.5 \\
\text { at } \% \mathrm{Sn}\end{array}$ & hP8 & $\mathrm{P} 63 / \mathrm{mmc}$ & D019 & $\begin{array}{c}\mathrm{Mg}_{3} \\
\mathrm{Cd}\end{array}$ & 1190 \\
\hline $\mathrm{Ni}_{3} \mathrm{Sn}_{2} \mathrm{HT}_{\mathrm{H}}$ & $\begin{array}{c}36.7 \sim 44 \\
\text { at } \% \mathrm{Sn}\end{array}$ & hP6 & $\mathrm{P} 63 / \mathrm{mmc}$ & $\mathrm{B}_{1}$ & $\mathrm{Ni}_{2} \mathrm{In}$ & 1540 \\
\hline $\mathrm{Ni}_{3} \mathrm{Sn}_{2} \mathrm{LT}_{\mathrm{L}}$ & $\begin{array}{c}39.3 \sim 41.1 \\
\text { at } \% \mathrm{Sn}\end{array}$ & oP20 & $\mathrm{P} 63 / \mathrm{mmc}$ & - & $\begin{array}{c}\mathrm{Ni}_{3} \mathrm{~S} \\
\mathrm{n}_{2} \\
\end{array}$ & 848 \\
\hline $\mathrm{Ni}_{3} \mathrm{Sn}_{4}$ & $\begin{array}{l}53 \sim 57 \\
\text { at\% Sn }\end{array}$ & $\mathrm{mC} 14$ & $\mathrm{C} 2 / \mathrm{m}$ & B20 & $\begin{array}{c}\mathrm{Ni}_{3} \mathrm{~S} \\
\mathrm{n}_{4} \\
\end{array}$ & 1069 \\
\hline FCC_A1 & $\begin{array}{c}0 \sim 0.05 \\
\text { at } \% \mathrm{Bi}\end{array}$ & cF4 & $\mathrm{Fm} \overline{3} \mathrm{~m}$ & A1 & $\mathrm{Cu}$ & 1728 \\
\hline $\mathrm{NiBi}$ & $\begin{array}{l}45 \sim 49 \\
\text { at } \% \mathrm{Bi} \\
\end{array}$ & $\mathrm{hP} 4$ & $\mathrm{P} 6 / \mathrm{mmc}$ & $\mathrm{B}_{1}$ & $\mathrm{NiAs}$ & 927 \\
\hline $\mathrm{NiBi}_{3}$ & 75 at $\% \mathrm{Bi}$ & oP16 & Pnma & $\mathrm{D}^{16_{2 h}}$ & $\begin{array}{c}\mathrm{CaLi} \\
\mathrm{Si}_{2} \\
\end{array}$ & 744 \\
\hline (Bi) & 100 at $\% \mathrm{Bi}$ & hR2 & $\mathrm{R} \overline{3} \mathrm{~m}$ & A7 & $\alpha$ As & 544.59 \\
\hline
\end{tabular}

Table 1. Crystal structures of pure components and binary phases in systems Ni-Sn, Bi-Ni and $\mathrm{Bi}-\mathrm{Sn}$ and temperatures of precipitations of the presented phases (Liu et al. 2004, Okamoto 2012)

The Gibbs energy of the liquid phase is described by the random substitutional solution model with Redlich-Kister polynomials. Taking an A-B-C system as an example, the Gibbs energy of the solution phase in the A-B-C system is expressed as follows:

$$
\begin{gathered}
G_{m}^{\phi}=x_{A}^{\phi 0} G_{A}{ }^{\phi}+x_{B}{ }^{\phi 0} G_{B}{ }^{\phi}+x_{C}{ }^{\phi 0} G_{C}{ }^{\phi}+R T\left(x_{A}{ }^{\phi} \ln x_{A}{ }^{\phi}+x_{B}{ }^{\phi} \ln x_{B}{ }^{\phi}+x_{C}{ }^{\phi} \ln x_{C}{ }^{\phi}\right)+G^{E}\left(T, x_{B}\right) \\
G^{E}\left(T, x_{B}\right)=x_{A}{ }^{\phi} x_{B}{ }^{\phi} L_{A, B}^{\phi}+x_{A}{ }^{\phi} x_{C}{ }^{\phi} L_{A, C}^{\phi}+x_{B}{ }^{\phi} x_{C}{ }^{\phi} L_{B, C}^{\phi}+x_{A}{ }^{\phi} x_{B}{ }^{\phi} x_{C}{ }^{\phi} L_{A, B, C}^{\phi}
\end{gathered}
$$




$$
\begin{gathered}
L_{i, j}^{\phi}=\sum_{m=0}^{n} L_{i, j}^{\phi}\left(x_{i}-x_{j}\right)^{m} \\
L_{A, B, C}^{\phi}=x_{A}{ }^{\phi 0} L_{A, B, C}^{\phi}+x_{B}{ }^{\phi 1} L_{A, B, C}^{\phi}+x_{C}{ }^{\phi 2} L_{A, B, C}^{\phi}
\end{gathered}
$$

Where $L_{i, j}(i, j=A, B, C)$ and $L_{A B C}$ are binary and ternary temperature-dependent interaction parameters optimized on the basis of the available thermodynamic and phase diagram data. For other phases, sublattice models are used.

\section{Results and discussion}

In Table 2, the optimized thermodynamic binary parameters and the ternary parameters obtained in this optimization are given only. The other optimized parameters were taken from the

\begin{tabular}{|c|c|}
\hline $\begin{array}{l}\text { Liquid (1 sublattice, sites: } 1 \text {, constituents: } \mathrm{Bi}, \mathrm{Ni}, \mathrm{Sn}) \\
\mathrm{L}^{\mathrm{L}} \mathrm{Bi,Ni, \textrm {Sn }}=(+38091.14-80 \times \mathrm{T}) \times \mathrm{Bi}+(-4000+0.4 \times \mathrm{T}) \times \mathrm{Ni}+(+5000) \times \mathrm{Sn}\end{array}$ & $\mathrm{O}^{\mathrm{a}}$ \\
\hline 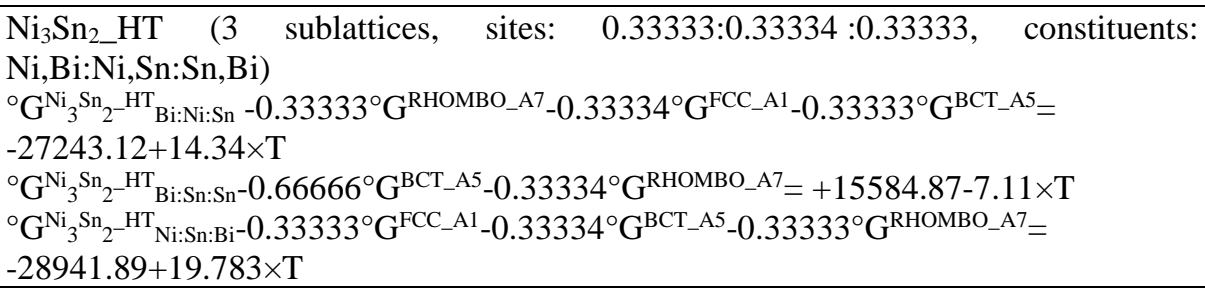 & $\begin{array}{l}\mathrm{O}^{\mathrm{a}} \\
\mathrm{O}^{\mathrm{a}} \\
\mathrm{O}^{\mathrm{a}}\end{array}$ \\
\hline 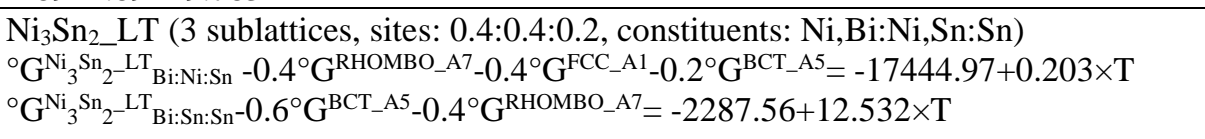 & $\begin{array}{l}\mathrm{O}^{\mathrm{a}} \\
\mathrm{O}^{\mathrm{a}}\end{array}$ \\
\hline 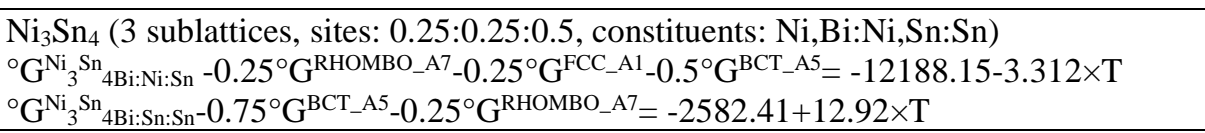 & $\begin{array}{l}\mathrm{O}^{\mathrm{a}} \\
\mathrm{O}^{\mathrm{a}} \\
\end{array}$ \\
\hline 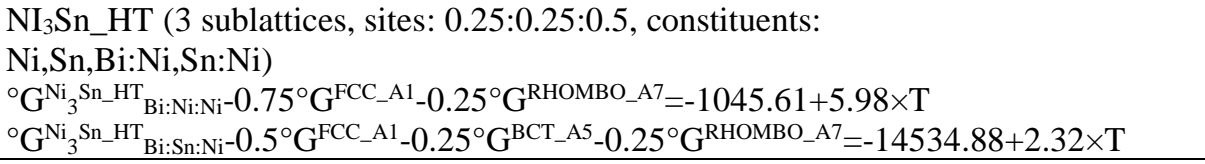 & $\begin{array}{l}\mathrm{O}^{\mathrm{a}} \\
\mathrm{O}^{\mathrm{a}} \\
\end{array}$ \\
\hline 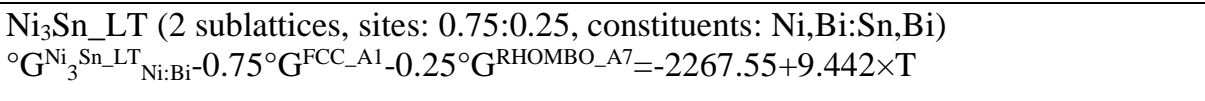 & $\mathrm{O}^{\mathrm{a}}$ \\
\hline 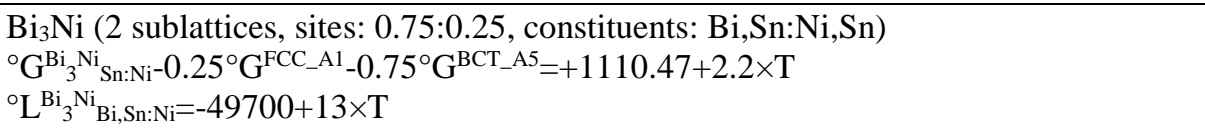 & $\begin{array}{l}\mathrm{O}^{\mathrm{a}} \\
\mathrm{O}^{\mathrm{a}}\end{array}$ \\
\hline 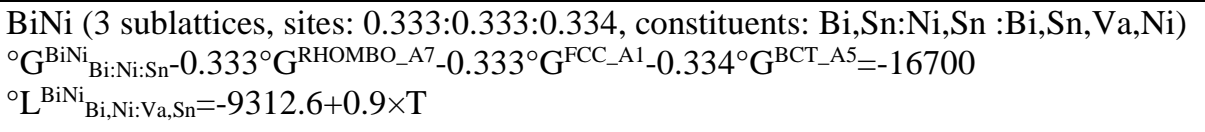 & $\begin{array}{l}\mathrm{O}^{\mathrm{a}} \\
\mathrm{O}^{\mathrm{a}}\end{array}$ \\
\hline 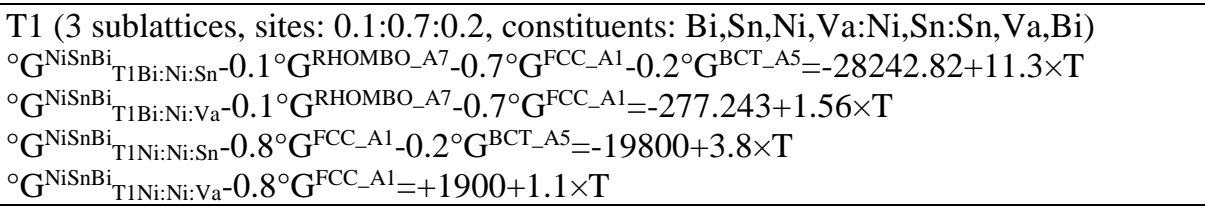 & $\begin{array}{l}\mathrm{O}^{\mathrm{a}} \\
\mathrm{O}^{\mathrm{a}} \\
\mathrm{O}^{\mathrm{a}} \\
\mathrm{O}^{\mathrm{a}}\end{array}$ \\
\hline
\end{tabular}
literature (Vassilev et al. 2009b, Liu et al. 2004, Vizdal et al. 2007, Dinsdale et al. 2008). 


\section{$\mathrm{O}^{\mathrm{a}}$ - optimized in this work value}

Table 2. Thermodynamic modelling of Ni-Sn-Bi ternary system of phases optimized in this work

Four isothermal sections at $723 \mathrm{~K}, 903 \mathrm{~K}, 973 \mathrm{~K}$ and $1273 \mathrm{~K}$ calculated using the parameters optimized in this work, are presented in Figs. 1-4. According to the thermodynamic description, some discrepancies in the solubility of $\mathrm{Sn}$ in the $\mathrm{NiBi}_{3}$ phase and $\mathrm{Bi}$ in the $\mathrm{Ni}_{3} \mathrm{Sn} \_\mathrm{LT}$ appeared according to the calculations. The solubility of $\mathrm{Sn}$ in $\mathrm{NiBi}_{3}$ phase is observed at a low temperature up to $573 \mathrm{~K}$. The main idea to calculating these isothermal sections was that the calculated results confirm experimental results from Vassilev et al. (2008, 2009a).

Figure. 1 presents the isothermal section at $723 \mathrm{~K}$ including the ternary compound $\mathrm{T} 1$ and is in a very good agreement with the experimental data (Vassilev et al. 2009a). In the calculated isothermal section at this temperature the solubility of $\mathrm{Sn}$ in $\mathrm{NiBi}_{3}$ and $\mathrm{Bi}$ in $\mathrm{Ni}_{3} \mathrm{Sn} \_\mathrm{LT}$ phases did not appear. In the other binary phases, $\mathrm{Ni}_{3} \mathrm{Sn}_{2} \mathrm{LT}, \mathrm{Ni}_{3} \mathrm{Sn}_{4}$ and $\mathrm{NiBi}$ the solubility of the third element was noticed (Vassilev et al. 2009a). Good agreement between the calculated and experimental results connected with the phase equilibria was observed.

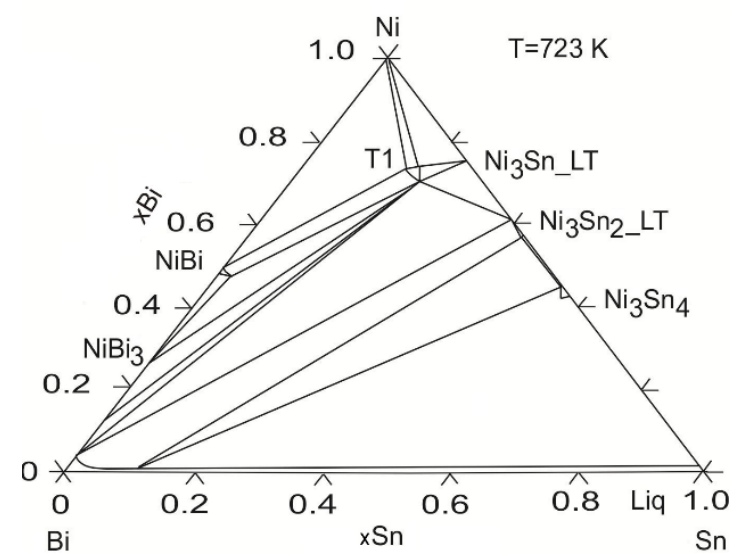

Fig. 1. Isothermal section of the system calculated at $723 \mathrm{~K}$

The ternary compound is observed at $903 \mathrm{~K}$ and $973 \mathrm{~K}$ (Fig. 2 and Fig. 3) but not at $1073 \mathrm{~K}$, hence it can be described as a low temperature phase, which does not exist above $1000 \mathrm{~K}$. The highest temperature, at which the ternary compound exists, is $973 \mathrm{~K}$ (Fig. 3), which is supported by both the calculations and the experimental data (Vassilev et al. 2008, 2009a). Figure 2 shows the binary phase fields between $\mathrm{Ni}_{3} \mathrm{Sn}_{2} \mathrm{HT}_{2} \mathrm{Ni}_{3} \mathrm{Sn}_{4}$ and the liquid phase (Vassilev et al. 2009). Ternary phase equilibria between T1-FCC_A-NiBi and T1-FCC_A1-Ni 3 Sn_LT appears. Figure 3 presents the isothermal section at $973 \mathrm{~K}$. According to the calculations up in this temperature, ternary compound $\mathrm{T} 1$ does appear. 


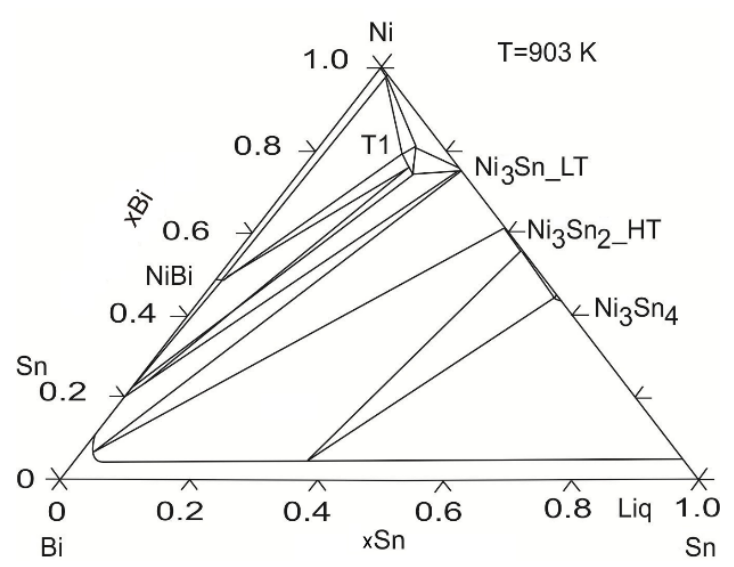

Fig. 2. Isothermal section of the system calculated at $903 \mathrm{~K}$

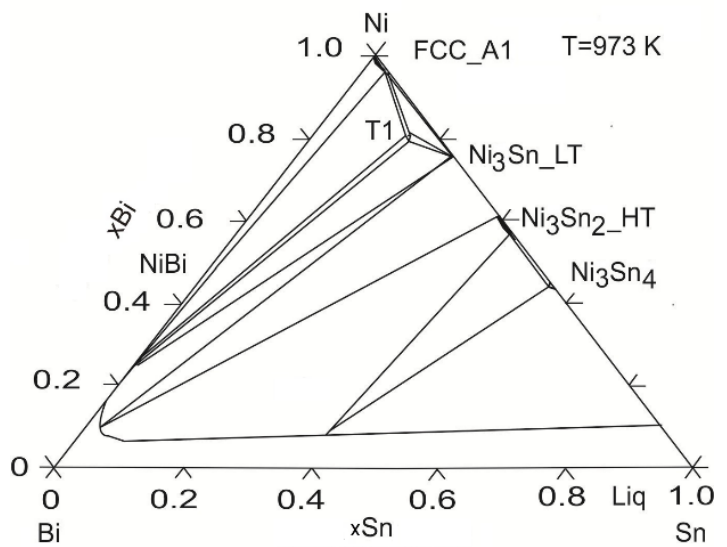

Fig. 3. Isothermal section of the system calculated at $973 \mathrm{~K}$

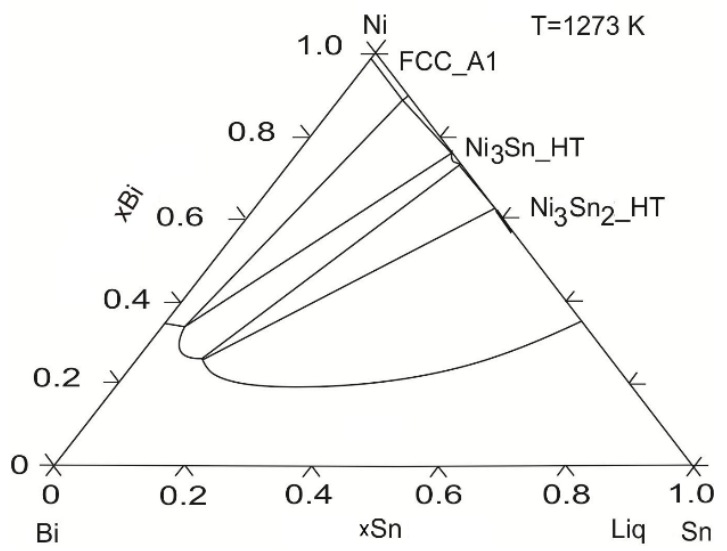

Fig. 4. Isothermal section of the system calculated at $723 \mathrm{~K}$

Figure 4 presents the calculated isothermal section at $1273 \mathrm{~K}$ at which temperature a small solubility of $\mathrm{Bi}$ in $\mathrm{Ni}_{3} \mathrm{Sn}_{2} \_\mathrm{LT}$ and $\mathrm{Ni}_{3} \mathrm{Sn} \_\mathrm{LT}$ is observed. Three phase equilibria fields between 
phases $\mathrm{Ni}_{3} \mathrm{Sn} \_\mathrm{HT}-\mathrm{Liq}-\mathrm{Ni}_{3} \mathrm{Sn}_{2} \_\mathrm{HT}$ and FCC_A1-Liq-Ni $\mathrm{N}_{3} \mathrm{Sn} \_\mathrm{HT}$ exist. The liquid phase exhibits a strange shape probably connected with the predicted miscibility gap in the Ni-Sn-Bi ternary system (Milcheva et al. 2011b).

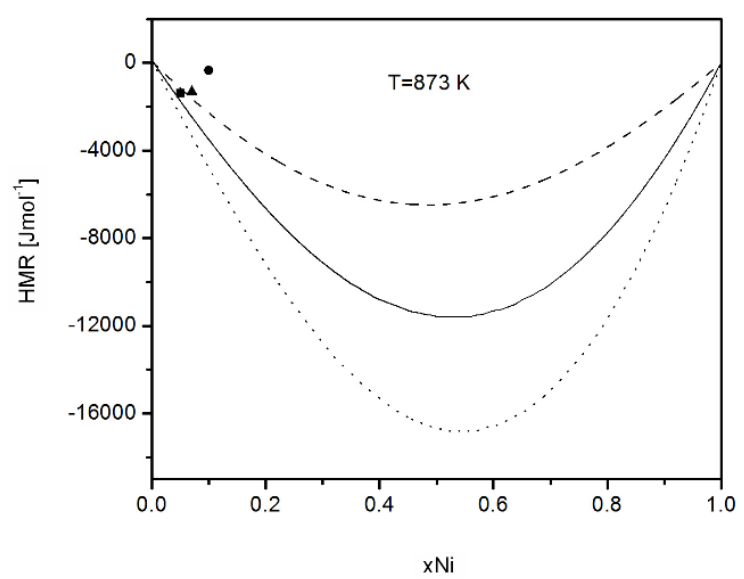

Fig. 5. Liquid phase integral enthalpies of formation at $873 \mathrm{~K}$ along cross-sections with $\mathrm{xNi}$ equal to: $0.05,0.07$ and 0.1 mole fractions

Figure 5 shows the calculated enthalpies of the liquid phase at $873 \mathrm{~K}$ compared with the experimental results (Vassilev et al. 2008). The three points represent the experimental enthalpies of formation (Vassilev et al. 2008) of the three binary nickel intermetallics, the solid, dotted and dashed curves are the calculated enthalpies of formation with different Sn:Bi mole fractions. The solid line corresponds to $\mathrm{Sn}: \mathrm{Bi}=0.51: 0.42$, the dashed line to $\mathrm{Sn}: \mathrm{Bi}=0.27: 0.63$ and dotted one to $\mathrm{Sn}: \mathrm{Bi}=0.70: 0.27$. The calculated enthalpies are slightly more negative than the experimental ones, but a reasonable agreement is observed when the Ni mole fraction is below 0.2 (Vassilev et al. 2008). The experimental and the calculated enthalpies of formation are shown in Table 3.

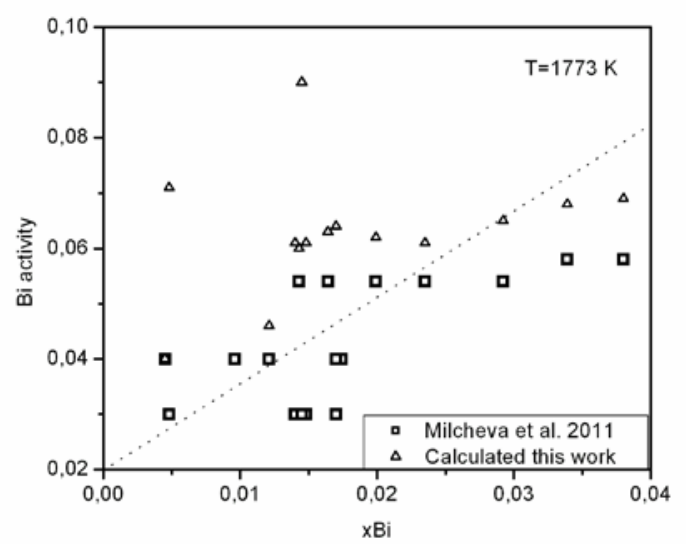

Fig. 6. Calculated in liquid phase Bi-activities at $1773 \mathrm{~K}$ (with ternary parameters obtained in this optimization), directly compared to the respective experimental data (Milcheva et al. 2011b) 
The Bi-activities at $1773 \mathrm{~K}$ calculated in this optimization compared with the experimental data (Milcheva et al. 2011b) are presented in Fig. 6. A positive deviation from the ideal behavior is observed.

\begin{tabular}{|c|c|c|c|c|c|c|}
\hline $\mathrm{N}$ & $\mathrm{xNi}$ & $\mathrm{xSn}$ & $\mathrm{xBi}$ & $\mathrm{T} \mathrm{K}$ & $\begin{array}{c}\text { HMR, exp } \\
{\left[\mathrm{Jmol}^{-1}\right]}\end{array}$ & $\begin{array}{l}\text { HMR, calc this } \\
\text { work }\left[\mathrm{Jmol}^{-1}\right]\end{array}$ \\
\hline 1 & 0.05 & 0.70 & 0.25 & 873 & -1390 & -2219 \\
\hline 2 & 0.07 & 0.51 & 0.42 & 873 & -1320 & -1693 \\
\hline 3 & 0.10 & 0.27 & 0.63 & 873 & -350 & -901 \\
\hline
\end{tabular}

Table 3. Comparative review of experimental enthalpies (Vassilev et al. 2008) and enthalpies calculated with parameters obtained in this optimization

A liquid phase miscibility gap in the Ni-Sn-Bi ternary system was predicted (Milcheva et al. 2011b), using the binary parameters to calculate the phase diagram only. A miscibility gap at $1610 \mathrm{~K}$ on the BiNi side of the phase diagram was confirmed by the current optimization. The ternary parameters for the liquid phase were used during the calculations. A two phase field equilibria between the liquid and an FCC_A1 phase appears at the same temperature.

\section{Conclusions}

The thermodynamic description of the ternary Ni-Sn-Bi system was performed using the Calphad method. In addition to the binary phases, a ternary compound T1 was included. It is considered non-stoichiometric and was described using the three-sublattice model. The models of some phases $\left(\mathrm{Ni}_{3} \mathrm{Sn} \_\mathrm{LT}, \mathrm{Ni}_{3} \mathrm{Sn} \_\mathrm{HT}, \mathrm{Ni}_{3} \mathrm{Sn}_{2} \_\mathrm{LT}, \mathrm{Ni}_{3} \mathrm{Sn}_{2} \_\mathrm{HT}, \mathrm{Ni}_{3} \mathrm{Sn}_{4}, \mathrm{NiBi}\right.$ and $\left.\mathrm{NiBi}_{3}\right)$ have been changed in order to comply with the present assessment.

Four ternary isothermal sections were calculated. The obtained results were compared with the experimental results and a reasonable correlation was found. In addition, the enthalpies of formation and Bi-activities were used for calculations. The solubility of the respective third element in two binary systems ( $\mathrm{Bi}$ in $\mathrm{Ni}-\mathrm{Sn}$ and $\mathrm{Sn}$ in $\mathrm{Bi}-\mathrm{Ni}$ ) were included in the presented optimization.

\section{References}

Andersson J, Helander T, Höglund L, Shi P, Sundman B (2002). Thermo-Calc \& DIictra, Computational Tools For Materials Science, Calphad, 26, 273-312.

Dinsdale A (1991). SGTE Data for pure elements, Calphad, 15, 317-425.

Dinsdale A, Watson A, Kroupa A, Vrestal J, Zemanova A, Vizdal J (2008). Atlas of Phase Diagrams for the Lead-Free Soldering, COST 531 (Lead-free Solders).

Kang S, Sarkhel A (1994). Lead (Pb)-free solders for electronic packaging, J. Electron. Mater., 23, 701-707.

Kang S, Rai R, Purushothaman S (1996). Interfacial reactions during soldering with lead-tin eutectic and lead $(\mathrm{Pb})$-free, tin rich solders, J. Electron. Mater., 25, 1113-1120.

Lee J, Chen S, Chang H, Chen C (2003). Reactive wetting between molten Sn-Bi and Ni substrate, J. Electron. Mater., 32, 117-122.

Liu H, Wang J, Jin Z (2004). Thermodynamic Optimization of the Ni-Sn Binary System, Calphad, 28, 363-370.

Lukas H, Fries S, Sundman B (2007). Computational Thermodynamics: The Calphad method, Cambridge University Press, Cambridge, UK. 
Massalski T (1996). CD ROM: Binary Alloy Phase Diagrams, ASM International, OH, USA.

Milcheva N, Broz P, Bur`sik J, Vassilev G (2011a). Thermochemical and phase diagram studies of the Bi-Ni-Sn system, Thermochimica Acta, 534, 41-50.

Milcheva N, Romanowska J, Vassilev G (2011b). Sn-Ni-Bi liquid phase thermodynamic properties, Cent. Eur. J. Chem., 9, 149-156.

Okamoto H (2012). Bi-Ni. Journal of Phase Equilibria and Diffusion, 33 (6), 492-492.

Seo S, Cho M, Lee H (2007). Thermodynamic Assessment of the Ni-Bi Binary System and Phase Equilibria of the Sn-Bi-Ni Ternary System, Journal of Electronic Materials, 36, 15361544.

Schmetterer C, Flandorfe H, Richter K, Saeed U, Kauffman M, Roussel P, Ipser H (2007). A new investigation of the system Ni-Sn, Intermetallics, 15, 869-884.

Vassilev G, Lilova K, Gachon J-C (2007). Supplementary X-ray studies of the Ni-Sn-Bi system, J. Min. Metall. B, 43, 141-150.

Vassilev G, Lilova K, Gachon J-C (2008). Calorimetric and phase equilibria studies of the NiSn-Bi system, Cryst. Res. Technol., 43, 980-985.

Vassilev G, Lilova K, Gachon J-C (2009a). Phase diagram investigation of the Ni-Sn-Bi system, J. Alloys Compd., 469, 264-269.

Vassilev G, Milcheva N, Record M, Mancheva R (2012). Diffusion couple studies of the Ni-BiSn system, J. Min. Metall. B, 48, 347-357.

Vassilev G, Gandova V, Docheva P (2009b). Comments and reconciliation of the Ni-Bi system thermodynamic reassessments, Cryst. Res. Technol., 44, 25-30.

Vizdal J, Braga M, Kroupa A, Richter K, Soares D, Malheiros L, Ferreira J (2007). Thermodynamic assessment of the Bi-Sn-Zn system, Calphad, 31, 438-448.

Zemanova A, Kroupa A, Dinsdale A (2012). Theoretical assessment of the Ni-Sn system, Monatsh Chem, 143, 1255-1261 